\title{
Well-differentiated fetal adenocarcinoma of the lung
}

INSERM

\section{Source}

INSERM. (1999). Orphanet: an online rare disease and orphan drug data base. Welldifferentiated fetal adenocarcinoma of the lung. ORPHA:284395

Well-differentiated fetal adenocarcinoma of the lung is a rare, primary, low-grade, bronchopulmonary neoplasm characterized by a well-circumscribed, usually large, pulmonary mass that is histologically composed of glycogen-rich neoplastic glands and tubules that resemble fetal lungs at 10 to 16 weeks of gestation and benign adjacent stroma. It typically presents with chest pain, cough, dyspnea, hemoptysis and/or generalized, non-specific symptoms, such as night sweats, lethargy, poor appetite and weight loss. 